\title{
Solitary arterial trunk with absence of the ascending aorta: Embryologic considerations
}

\author{
Alejandro R. Peirone, MD, ${ }^{a}$ Lisa K. Hornberger, MD, ${ }^{a}$ Shi-Joon Yoo, MD, ${ }^{a, b, c}$ Glen S. Van Arsdell, MD, ${ }^{b}$ and \\ Robert M. Freedom, MD, ${ }^{a, b, c}$ Toronto, Ontario, Canada
}

From the Division of Cardiology, ${ }^{\text {a Division }}$ of Cardiac Surgery, ${ }^{\mathrm{b}}$ Department of Paediatrics, and Department of Diagnostic Imaging, ${ }^{c}$ The Hospital for Sick Children, University of Toronto, Toronto, Ontario, Canada.

Received for publication Aug 16, 2001; accepted for publication Dec 14, 2001.

Address for reprints: Lisa K. Hornberger, MD, Division of Cardiology, The Hospital for Sick Children, 555 University Ave, Toronto, Ontario M5G 1X8, Canada (E-mail: hornberg@ sickkids.on.ca).

J Thorac Cardiovasc Surg 2002;123:993-5

Copyright $\odot 2002$ by The American Association for Thoracic Surgery

$0022-5223 / 2002 \$ 35.00+0 \quad \mathbf{1 2 / 5 4 / 1 2 2 5 4 1}$

doi:10.1067/mtc.2002.122541

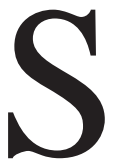

olitary arterial trunk describes a form of ventriculoarterial connection in which a single great artery arises from the base of the heart. A solitary arterial trunk usually represents a common arterial trunk $\mathrm{k}^{1}$ or an aorta in the setting of absent main and branch pulmonary arteries. ${ }^{2}$ We describe herein a very unusual case of solitary arterial trunk that gives rise to a single coronary artery and branch pulmonary arteries and in which there is absence of the ascending aorta, with the totality of the head and neck vessels arising from the descending aorta.

We present the surgical approach and discuss the embryologic possibilities, including the role of a persistent fifth or distal sixth aortic arch in common arterial trunk versus a unique solitary pulmonary trunk in the pathogenesis of the present case.

\section{Clinical Summary}

A male infant was born at term weighing $3400 \mathrm{~g}$. One day after birth, he became tachypneic and tachycardic and had signs of poor peripheral perfusion. An echocardiogram demonstrated evidence of a ductus arteriosus-dependent single-ventricle lesion and ductal constriction. Prostaglandin therapy was initiated, and the patient was transferred to our institution for further medical and surgical management.

Echocardiography performed on arrival revealed levocardia with atrial situs solitus. The atrioventricular connection was concordant. The right atrium and right ventricle were dilated. The left atrium and left ventricle were severely hypoplastic, and there was mitral atresia. The atrial septum was deviated to the left side. The right lower and middle pulmonary veins connected to the right and the rest of the pulmonary veins connected to the left of the atrial septum. A small ventricular septal defect was present immediately below the atretic mitral valve. A solitary arterial trunk arose exclusively from the right ventricle. The semilunar valve consisted of 3 evenly divided leaflets. It was neither stenotic nor regurgitant. A single coronary artery arose from the posterior and leftward sinus and gave rise to the left anterior descending, circumflex, and right coronary arteries. The right and left pulmonary arteries originated separately but close together from the posterior wall of the solitary arterial trunk immediately above the sinotubular junction. Distal to the origin of the pulmonary arteries, the trunk formed an arch on the left side of the trachea and had continuity with the descending aorta through a constricted connecting vessel, which responded to prostaglandins (Figure 1, $A$ and $B$ ). From the proximal descending aorta at its junction with the arch, 2 branches arose: a common stem for the right innominate and left carotid arteries and a separate left subclavian artery. The right innominate artery was in parallel with the arch connecting the solitary arterial trunk and descending aorta. No ascending aorta could be seen. Magnetic resonance imaging with bolus injection of $0.3 \mathrm{mmol} / \mathrm{kg}$ gadopentate confirmed the echocardiographic findings (Figure 1, $C$ ).

The patient underwent single-ventricle palliation on day 10 of life, at which time the anatomy was again confirmed. At operation, the connecting vessel between the arterial trunk and the descending aorta was resected to prevent postoperative constriction. The arch was reconstructed by using a homograft patch. The pulmonary arteries were disconnected from the trunk and anastomosed to each other, and a modified right Blalock-Taussig shunt was 

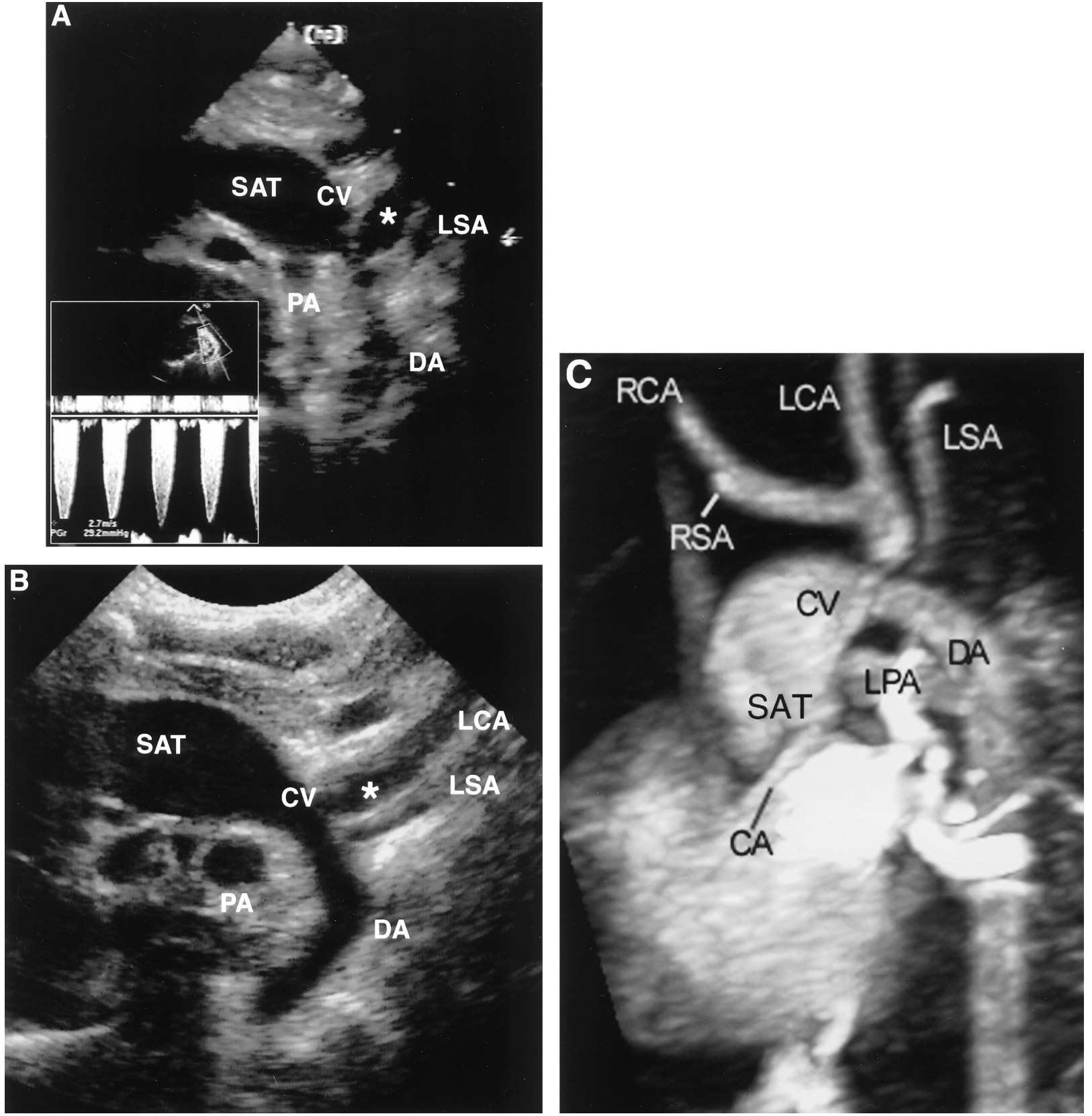

Figure 1. Echocardiographic suprasternal long-axis view before $(A)$ and after $(B)$ initiation of the prostaglandin infusion. A connecting vessel (CV) links the solitary arterial trunk (SAT) to the descending aorta (DA), forming an arch. A common stem (asterisk) arises from the descending aorta and gives rise to all branches to the head and neck, except the left subclavian artery (LSA), which has a separate origin. Right carotid and right subclavian arteries are out of plane in these images. Initially, the connecting vessel was anatomically narrowed, and the Doppler gradient from the solitary arterial trunk to the descending aorta was $29 \mathrm{~mm} \mathrm{Hg}$ (A). After initiation of prostaglandin therapy, there was an increase in the diameter of the connecting vessel, and the gradient resolved (B). C, Contrast-enhanced magnetic resonance angiogram. Reformatted image shows the solitary arterial trunk linked to the descending aorta through a connecting vessel. A common stem arises from the descending aorta and gives rise to the left carotid artery (LCA), right carotid artery (RCA), and right subclavian artery (RSA). The left subclavian (LSA) artery has a separate origin. A single coronary artery (CA) is seen. $L P A$, Left pulmonary artery; $P A$, pulmonary artery. 


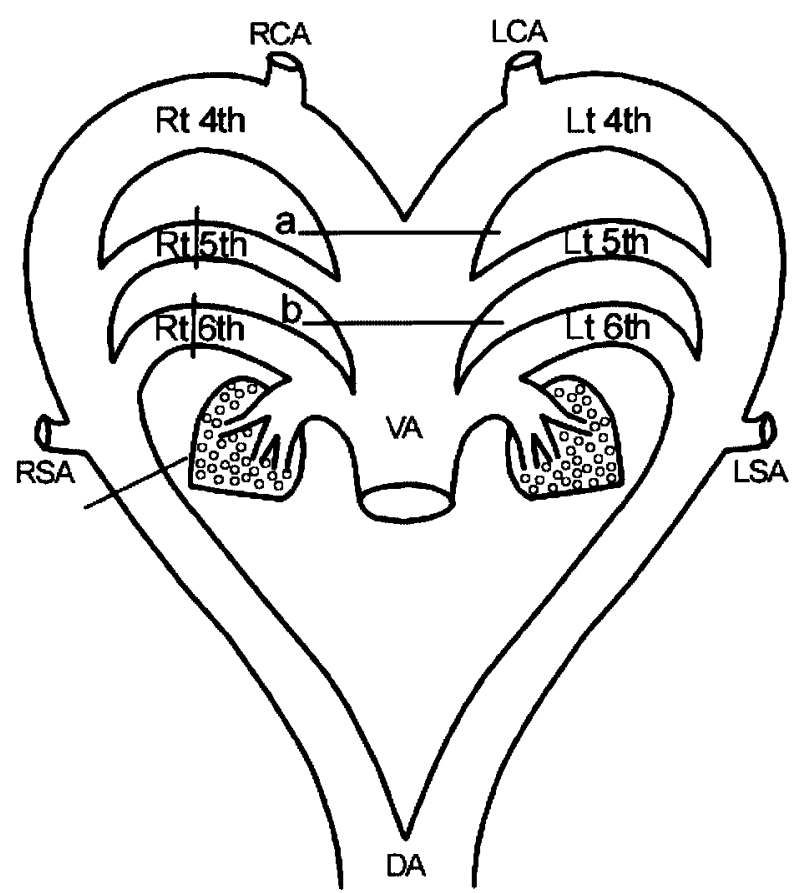

Figure 2. Diagram of a double aortic arch plan showing basic embryonic development. The vascular channels indicated by lines are considered to have regressed. Lines $\boldsymbol{a}$ and $\boldsymbol{b}$ are 2 possible levels of regression of the ventral aorta. If the regression occurred at level $a$, the connecting vessel would be a fifth aortic arch; on the other hand, if the regression was located at level $b$, the connecting vessel would be a persistent ductus arteriosus. $D A$, Dorsal aorta; $L C A$, left carotid artery; $R C A$, right carotid artery; $L S A$, left subclavian artery; $R S A$, right subclavian artery; $L t$, left; $R t$, right; $V A$, ventral aorta.

placed. An unrestrictive interatrial communication was created with extensive atrial septectomy.

There were no complications during the postoperative course, and the patient was discharged within 3 weeks. At the time of this report, the patient has already undergone successful bidirectional cavopulmonary connection.

\section{Discussion}

In this report we demonstrate a very unusual and previously undescribed form of solitary arterial trunk, the anatomy of which was clearly delineated by means of echocardiography and magnetic resonance imaging. We considered 2 possible embryologic causes for this lesion: a common arterial trunk versus an isolated pulmonary arterial trunk with absence of the ascending aorta and anomalous single coronary artery, in either case with a persistent fifth or distal sixth aortic arch connecting with the descending aorta.

As a common arterial trunk, there could have been 2 sites of regression of the embryologic arches (Figure 2). First is a regression of the common stem of the proximal ventral aorta between the fourth and fifth arches, with a persistence of the ipsilateral fifth arch providing the ventral aorta-dorsal aorta connection (Figure 2, level a). A persistent fifth arch is histologically nearly indistinguishable from a ductus arteriosus ${ }^{3,4}$ and has been shown to respond in a similar fashion to prostaglandin therapy. ${ }^{5}$ Second, if the regression of the ventral aorta would have occurred between the sixth and fifth arches with persistence of the distal part of the sixth arch, the connecting vessel would be a patent ductus arteriosus (Figure 2, level b). Although different types of interrupted aortic arches have been described in common arterial trunk, ${ }^{1}$ an interruption proximal to the brachiocephalic artery has never been shown.

This case could also represent a single pulmonary trunk with an absent ascending aorta and anomalous origin of a single coronary artery. Two previous reports document origin of the coronary arteries from the main pulmonary artery in the presence of aortic atresia with a hypoplastic left heart.6,7 In both, however, an ascending aorta was identified, making the absence of the ascending aorta again the most unique feature of the present case.

In summary, we present a unique case of solitary arterial trunk with absence of the ascending aorta and origin of the brachiocephalic vessels from the descending aorta. Arch reconstruction with the proximal solitary arterial trunk with detachment and anastomosis of the branch pulmonary arteries resulted in a successful first stage in single-ventricle palliation.

We thank Hawon Yoo for the preparation of the diagram.

\section{References}

1. Calder L, Van Praagh R, Van Praagh S, Sears WP, Corwin R, Levy A, et al. Truncus arteriosus communis: clinical, angiocardiographic and pathologic findings in 100 patients. Am Heart J. 1976;92:23-38.

2. Rossi M, Rossi Filho R, Ho SY. Solitary arterial trunk with pulmonary atresia and arteries with supply to the left lung from both an arterial duct and systemic-pulmonary collateral. Int J Cardiol. 1988;20:145-8.

3. Silver MM, Freedom RM, Silver MD, Olley PM. The morphology of the human newborn ductus arteriosus: a reappraisal of its structure and closure with special reference to prostaglandin $\mathrm{E}_{1}$ therapy. Hum Pathol. 1981;12:1123-36.

4. Freedom RM, Silver M, Miyamura H. Tricuspid and pulmonary atresia with coarctation of the aorta: a rare combination possibly explained by persistence of the fifth aortic arch with a systemic-topulmonary arterial connection. Int J Cardiol. 1989;24:241-5.

5. Zartner P, Schneider MBE, Bein G. Prostaglandin $\mathrm{E}_{1}$ sensitive persistent fifth aortic arch type 2. Heart. 2000;84:141.

6. Bharati S, Szarnicki RJ, Popper R, Fryer A, Lev M. Origin of both coronary arteries from the pulmonary trunk associated with hypoplasia of the aortic tract complex: a new entity. J Am Coll Cardiol. 1984;3: 437-41.

7. Ito T, Niino M, Ishikawa J, Matsumoto S, Matsuura T, Aoi T, et al. Hypoplastic left heart syndrome with a single coronary artery originating from the pulmonary artery. Acta Pediatr Jpn. 1995;35:61-3. 